\title{
Getting from Here to There: Spatial Anxiety, Wayfinding Strategies, Direction Type, and Wayfinding Efficiency
}

\author{
Alycia M. Hund and Jennifer L. Minarik \\ Illinois State University
}

\begin{abstract}
We investigated the efficiency with which men and women find their way to novel destinations using directions containing landmarks or cardinal descriptors and how such wayfinding performance is related to differences in spatial anxiety and wayfinding strategies. In two experiments, participants navigated through a model town using landmark or cardinal directions. Men and women were faster and more accurate when navigating based on cardinal directions than when navigating based on landmark directions. In addition, participants who reported greater spatial anxiety made significantly more navigation errors. As reliance on orientation strategies increased, navigation efficiency increased, suggesting that wayfinding strategies are related to navigation performance. These findings are discussed in relation to broader theoretical ideas concerning the dynamics of wayfinding processes.
\end{abstract}

Keywords: Wayfinding, spatial anxiety, spatial orientation.

Finding our way from place to place is essential to everyday functioning. Often, people rely on information from others to help navigate, especially when trying to reach unfamiliar destinations (Allen, 1999a). For example, people follow directions to get to convention centers and tourist sites in unfamiliar cities. Although the goal of such wayfinding tasks is to reach the desired destination, navigation speed and accuracy also may be important. Finding the convention center quickly and accurately can mean the difference between arriving on time or late for an important meeting or presentation. One goal of the present

Correspondence concerning this article should be addressed to Alycia M. Hund, Department of Psychology, Illinois State University, Campus Box 4620, Normal, IL, 61790-4620; email: amhund@ilstu.edu. 


\section{HUND, MINARIK}

investigation was to examine how wayfinding strategies (e.g., orientation and route strategies) and anxiety are related to navigation performance. A second goal was to determine the efficiency with which men and women navigate using directions involving landmarks or cardinal descriptors. A final goal was to specify how navigation efficiency changes over time, providing valuable insights into the dynamics of wayfinding.

People can use a variety of cues when giving directions to help others find unfamiliar destinations. For instance, they might provide details regarding distance and direction of travel, salient landmarks, and specific street names (Denis, Pazzaglia, Cornoldi, \& Bertolo, 1999; Mark \& Gould, 1995; Ward, Newcombe, \& Overton, 1986; see Plumert, Carswell, DeVet, \& Ihrig, 1995; Taylor \& Naylor, 2002; Taylor, Naylor, \& Chechile, 1999; Taylor \& Tversky, 1992 for related findings involving spatial descriptions). In one study, Ward et al. (1986) asked participants to learn a map containing many landmarks and roads and then to give directions from a starting location to a destination. Men provided more cardinal descriptors and mileage information than did women. In a similar study, MacFadden, Elias, and Saucier (2003), asked participants to study a set of routes on a map. Participants then wrote a set of directions to help someone navigate from the starting location to the destination. Men included cardinal descriptors and distance more frequently than women (e.g., Go north 10 feet). Women included landmarks and left-right turns more often than men (e.g., Turn right towards the library; for related results, see Lawton, 1994, 1996, 2001; Miller \& Santoni, 1986; Pazzaglia \& DeBeni, 2001; Sholl, Acacio, Makar, $\&$ Leon, 2000). Together, these findings highlight the types of information men and women provide when giving directions to help others navigate.

An important next step in understanding navigation abilities is to understand the features that render directions effective from a listener's perspective (Ward et al., 1986). That is, how effectively can people navigate using directions containing various cues? Recent research has focused on navigation using two common direction types: landmark descriptors (e.g., go toward the arena on Main St.) and cardinal descriptors (e.g., go east on Main St.; Jansen-Osmann, 2002; Lawton, 1994, 1996; MacFadden et al., 2003; Pazzaglia \& DeBeni, 2001; Saucier et al., 2002; Sholl et al., 2000). Landmark descriptors commonly are used when describing routes from the perspective of a traveler moving from place to place, whereas cardinal descriptors frequently are used when describing a layout from a global frame of reference. These two modes of description parallel the theoretical distinction between configural/survey and route knowledge (e.g., Golledge, 1987, 1999; Hirtle \& Hudson, 1991; Pazzaglia \& DeBeni, 2001; Shelton \& McNamara, 2004; Siegel \& White, 1975; Taylor \& Tversky, 1996) and between orientation/survey and route strategies for wayfinding (e.g., Lawton, 1994, 1996; Lawton \& Kallai, 2002; Pazzaglia \& DeBeni, 2001) often discussed in the literature.

In one recent study, for example, Saucier et al. (2002) examined the efficiency with which men and women navigated using directions involving landmarks or Euclidean descriptors (e.g., distance information and cardinal 
directions). In Experiment 1, participants navigated to unknown destinations on campus by reading directions one segment at a time. Women who followed directions containing Euclidean descriptors navigated more slowly than did women and men who followed directions containing landmark descriptors. Experiment 2 involved a novel matrix navigation task. Participants followed landmark or Euclidean directions to find a destination on a small $(25 \mathrm{~cm} \times 23$ cm) $10 \times 10$ matrix filled with icons. Men were faster and more accurate in the Euclidean condition than in the landmark condition. In contrast, women were faster and more accurate in the landmark condition than in the Euclidean condition. These findings reveal interesting gender differences in navigation abilities based on cardinal and landmark directions.

In addition to documenting navigation differences due to direction type and gender, researchers have begun to examine individual differences related to wayfinding strategies and spatial anxiety (e.g., Bryant, 1982; Kozlowski \& Bryant, 1977; Lawton, 1994, 1996; Lawton, Charelston, \& Zieles, 1996; Lawton \& Kallai, 2002; for a recent review, see Montello, Lovelace, Golledge, \& Self, 1999). For example, Lawton and Kallai (2002) examined individual differences in wayfinding strategies and spatial anxiety. They asked participants to report which strategy they prefer when navigating through the environment: orientation or route. Orientation strategies involve maintaining a sense of one's own position in relation to a given a point (e.g., "I keep track of the direction [north, south, east, or west] in which I am going."). Route strategies involve using a particular route to get from place to place (e.g., "I ask for directions telling me whether to turn right or left at particular landmarks."). Men reported using orientation strategies more than did women, whereas women reported using route strategies more than did men. Participants also completed measures of spatial anxiety and general anxiety. The spatial anxiety scale measured the extent to which participants felt anxious when following directions and navigating in unfamiliar environments. Women reported more spatial anxiety (but not general anxiety) than did men. These findings suggest that there are interesting individual differences in wayfinding strategies and spatial anxiety.

In a related study, Lawton (1996) assessed the relations among wayfinding strategies, spatial anxiety, and wayfinding performance. Participants learned a route through one floor of an academic building. Then, they were asked to point to the four landmarks from an unfamiliar location on the floor. The landmarks were not visible from this location, so participants needed to rely on their memory of the locations. Participants also completed self-report measures of wayfinding strategies and spatial anxiety. Of central importance was the relation between these self-report measures and pointing accuracy. As reliance on orientation strategies increased, pointing accuracy to unseen locations also increased; however, reported use of route strategies was unrelated to pointing error. Moreover, as spatial anxiety increased, pointing accuracy decreased. These findings support the claim that wayfinding strategies and spatial anxiety are related to spatial behavior. Nonetheless, findings from other studies have not revealed such robust relations (Prestopnik \& Roskos-Ewoldsen, 2000; Saucier et 


\section{HUND, MINARIK}

al., 2002). For example, Saucier et al. (2002) examined the relation between spatial anxiety and wayfinding speed and accuracy when following directions to navigate on campus. Contrary to predictions, spatial anxiety was unrelated to navigation efficiency. Thus, evidence concerning the relations among spatial anxiety, wayfinding strategies, and everyday navigation performance is mixed, perhaps reflecting the complexities of these relations.

One goal of the present investigation was to investigate the relations among spatial anxiety, wayfinding strategies, and navigation efficiency. A second goal was to examine the efficiency (i.e., speed and accuracy) with which men and women navigate to unfamiliar destinations using directions containing cardinal or landmark descriptors and to specify the nature of gender differences in navigation efficiency using these cues. A third goal was to specify how navigation efficiency changes over time during our task. As such, this investigation would provide valuable information about how multiple cues are related to wayfinding performance as it evolves over time, thereby supporting a dynamic view of wayfinding processes. Toward this end, we examined how wayfinding strategies and spatial anxiety are related to everyday navigation performance. Participants read sets of directions (one step at a time) printed on note cards and moved a toy car so that it followed the directions in a fictitious model town. Using a fictitious space allowed us to control participants' familiarity with the space in which they navigated. Moreover, it allowed us to control the layout and inclusion of information in the space. We carefully scripted the directions so they were the same except for the critical manipulation of information type (e.g., landmarks or cardinal descriptors). Because our goal was to compare navigation efficiency using landmark and cardinal descriptors, we removed references to left and right turns so that the directions contained only cardinal descriptors or landmarks, as well as street names.

We predicted that self-reports of wayfinding strategies would be related to navigation efficiency in our task. In particular, as preferences for orientation strategies increased, we expected that navigation efficiency using cardinal directions would increase (e.g., faster navigation times and fewer errors). Similarly, as preferences for route strategies increased, navigation efficiency using landmark directions also should increase. We also predicted that participants who reported greater spatial anxiety would be less efficient navigators. ${ }^{1}$ In addition, we expected that navigation efficiency would differ depending on gender and direction type such that women would be faster and

\footnotetext{
${ }^{1}$ Although it is unclear whether the relation between spatial anxiety and spatial performance is linear in nature, or more complex, such as the curvilinear relation between general anxiety and performance (i.e., optimal performance at midlevels of anxiety), we predicted a negative linear relation between spatial anxiety and spatial performance based on previous findings reported in the literature in which spatial performance declines as spatial anxiety increases. Despite previous findings differentiating spatial anxiety and general anxiety (e.g., Lawton \& Kallai, 2002), future work is needed to further clarify these relations.
} 
more accurate when following directions containing landmarks than when following directions containing cardinal directions, whereas men would be faster and more accurate when following directions containing cardinal directions than when following directions containing landmarks. Finally, we expected that navigation efficiency would improve over trials, suggesting a key role for experience. Together, these findings would strengthen existing theoretical and empirical ideas concerning the dynamics of wayfinding.

\section{EXPERIMENT 1}

\section{Method}

\section{Participants}

Sixty-four participants (32 men and 32 women) volunteered to participate in this study. Data from two additional female participants were excluded because their average navigation times were greater than two standard deviations above the mean. Data from one additional male participant was excluded because of missing questionnaire data. Participants were students at a large, public Midwestern University recruited through the Department of Psychology research participant pool. Their ages ranged from 19 to 47 years $(M=21$ years 7 months). Participants received extra credit in their psychology courses.

\section{Materials and Apparatus}

A $122 \mathrm{~cm} \times 198 \mathrm{~cm}(4 \mathrm{ft} \times 6.5 \mathrm{ft})$ piece of white plywood was used as the fictitious model town. The plywood was placed on top of a table, allowing the participants to move the car easily around the town. The town contained 17 landmarks and 30 streets that were fictitiously named and arranged. The streets were constructed using blue masking tape with names such as Main St., Division St., Lemon Ave., and Elm St. The landmarks were made using wooden blocks with unique pictures taped on top of them. The landmarks included a church, a monument, a school, a mall, and a courthouse (see Figure 1). A toy car was used by the participants during navigation. The experimenter used a stopwatch to record the time for each trial.

A bound set of $9 \mathrm{~cm} \times 13 \mathrm{~cm}(3.5 \mathrm{in} . \times 5$ in.) note cards containing written descriptions of 12 routes was used during navigation. Each route included five note cards, and each note card contained one line of the directions. This allowed participants to make only one move at a time and ensured that they were unaware of the final destination until they reached the last leg of the directions.

\section{Design and Procedure}

Navigation task. On each trial, participants followed a specific set of directions by moving a toy car from a starting location to a destination in the fictitious model town. Each trial involved one route, which included five lines of directions. On half of the trials, all of the directions contained landmarks (e.g., "Turn toward the church on Memory Lane"), whereas on the remaining trials, 


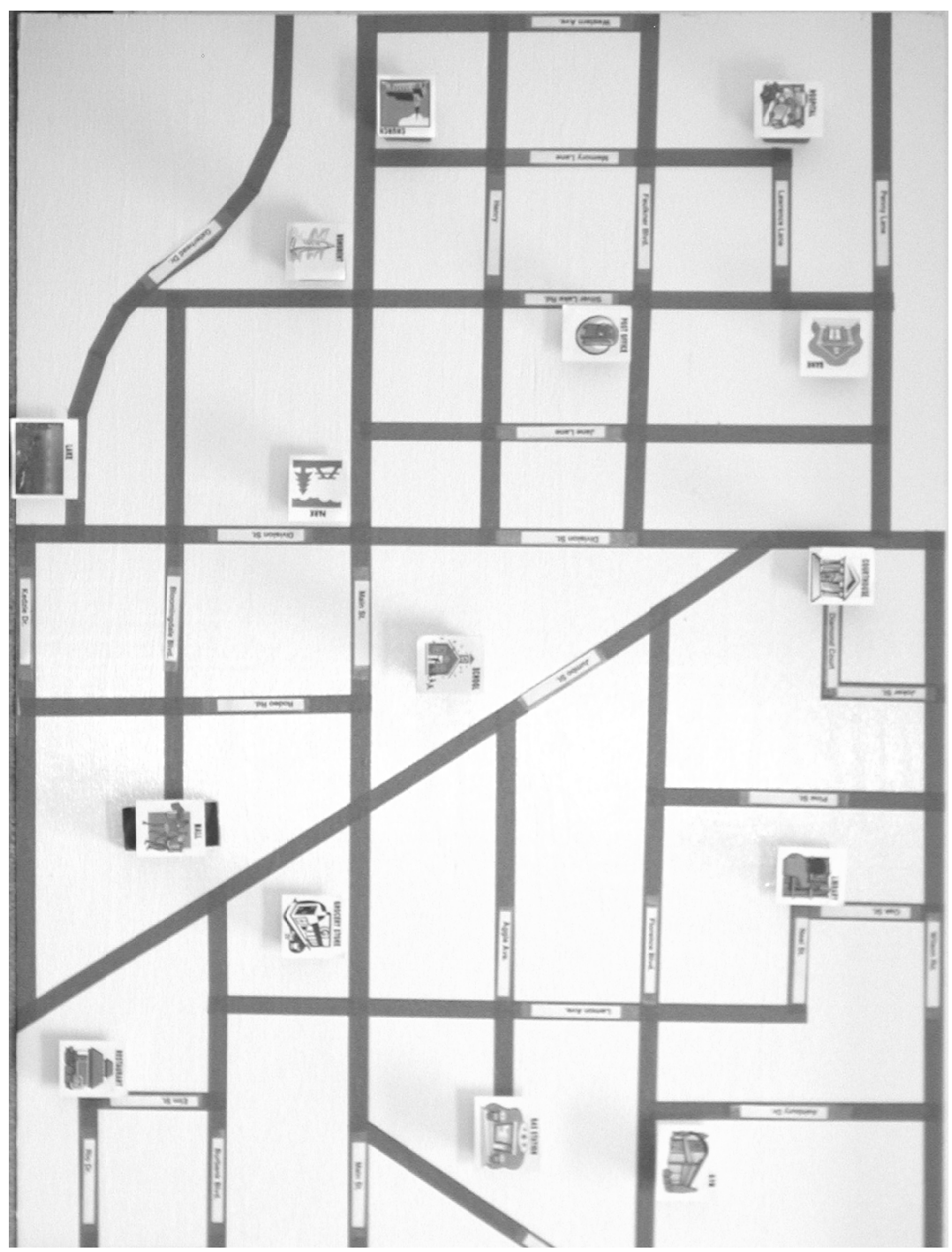

Figure 1. Overhead view of the fictitious model town, including streets and landmarks.

they contained cardinal descriptors (e.g., "Go north on Lemon Ave."). Thus, information type was manipulated as a within-subjects variable. The assignment of routes (A or B) to information type and the order of routes (i.e., $\mathrm{AB}$ or $\mathrm{BA}$ ) were counterbalanced across participants, leading to four combinations of directions and orders: Landmark A followed by Cardinal B, Landmark B 
followed by Cardinal A, Cardinal A followed by Landmark B, and Cardinal B followed by Landmark A. Table 1 includes detailed descriptions of all routes and instructions included.

During the familiarization phase, the experimenter brought the participants to the south end of the model town and told them which way was north, east, south, and west. The experimenter then showed them each landmark (in a random order) and gave them 30 seconds to become familiar with the town. On each trial, the experimenter placed the car in the starting position, and said, "Go." The participants then read the directions printed on the first card and moved the car so it followed the directions. They continued flipping the cards one at a time and moving the car so it followed the directions until they reached the card that said, "Stop." This card indicated they had reached their final destination. For most routes, participants needed to move around the outside of the model town to complete the route (see Table 1 and Figure 1). They were required to keep the car on the streets in the model town at all times, and to maintain contact with the car when it was moving.

The experimenter recorded the navigation time for each trial from the starting location (i.e., when the experimenter said, "Go") to the destination (i.e., when the participants said, "Stop"). We averaged the times across the 6 trials containing each direction type to calculate two mean navigation times for each participant. Subsequent calculations were used to determine the mean navigation time for the first three and last three trials involving each type of information. The experimenter also recorded navigation errors during each trial, including backing up, wrong turns, wrong streets, wrong destination, stopping short of the destination, and quitting. A back up occurred when participants retraced their path by reversing the toy car. A wrong turn occurred when participants turned the car the wrong way on a (correct) street. A wrong street was when the participants turned on the wrong street. The wrong destination was defined as stopping the toy car at an incorrect destination. Stopping short was coded when participants stopped the car more than one toy car length prior to the destination. Quitting occurred when participants gave up on the route and stopped at a random location. We summed the total number of errors for the 6 trials containing each direction type to calculate two navigation error scores for each participant.

Spatial Anxiety Scale. Participants completed an 8-item questionnaire (Lawton, 1994) designed to assess spatial anxiety in a variety of wayfinding situations (e.g., "Rate the level of anxiety you think you would feel when finding your way around an unfamiliar mall”). Responses to the eight items were summed. The higher the total number, the more anxiety the participant reported when engaged in wayfinding tasks in unfamiliar environments.

Wayfinding Strategy Scale. Participants were asked to complete a 16-item questionnaire designed to assess wayfinding strategies (Lawton \& Kallai, 2002). It included questions such as, I ask for directions telling me to turn right or left at particular landmarks, and Whenever I make a turn, I know which direction I am facing. Responses to the 11 questions related to orientation strategies 


\section{HUND, MINARIK}

\section{Table 1}

\section{Summary of Routes}

\begin{tabular}{l}
\hline Route Starting Point \\
\hline A1 Pine St. and Florence Blvd. facing east \\
Go straight on Florence Blvd. Turn toward the gas station on Lemon Ave. Turn toward \\
the grocery store on Main St. Turn onto Rodeo Rd. Turn toward the mall on \\
Bloomingdale Blvd. to get to the mall.
\end{tabular}

Go east on Florence Blvd. Turn south on Lemon Ave. Turn west on Main St. Turn south on Rodeo Rd. Turn east on Bloomingdale Blvd. to get to the mall.

A2 Wilson Rd. and Pine St. facing south

Go straight on Pine St. Turn toward the gym on Florence Blvd. Turn toward the gas station on Lemon Ave. Turn toward the park on Main St. Turn toward the church on Memory Lane to get to the church.

Go south on Pine St. Turn east on Florence Blvd. Turn south on Lemon Ave. Turn west on Main St. Turn north on Memory Lane to get to the church.

A3 Penny Lane at edge of town facing east

Go toward the bank on Penny Lane. Turn toward the park on Jane Lane. Turn toward the grocery store on Main St. Turn toward the gas station on Lemon Ave. Turn toward the school on Aggie Ave. to get to the school.

Go east on Penny Lane. Turn south on Jane Lane. Turn east on Main St. Turn north on Lemon Ave. Turn west on Aggie Ave. to get to the school.

A4 Bloomingdale Blvd. and Rodeo Rd. facing north

Go toward the school on Rodeo Rd. Turn toward the park on Main St. Turn at the church onto Memory Lane. Turn onto Lawrence Lane. Turn toward the bank on Silver Lake Rd. to get to the bank.

Go north on Rodeo Rd. Turn west on Main St. Turn north on Memory Lane. Turn east on Lawrence Lane. Turn north on Silver Lake Rd. to get to the bank.

A5 Henry and Western Ave. facing east

Go straight on Henry. Turn toward the park on Division St. Turn toward the grocery store on Main St. Turn toward the gas station on Lemon Ave. Turn toward the gym on Florence Blvd. to get to the gym.

Go east on Henry. Turn south on Division St. Turn east on Main St. Turn north on Lemon Ave. Turn east on Florence Blvd. to get to the gym.

A6 Faulkner Blvd. and Memory Lane facing east

Go straight on Faulkner Blvd. Turn toward the park on Jane Lane. Turn toward the grocery store on Main St. Turn toward the restaurant on Lemon Ave. Turn toward the tavern on Burbank Blvd. to get to the tavern.

Go east on Faulkner Blvd. Turn south on Jane Lane. Turn east on Main St. Turn south on Lemon Ave. Turn east on Burbank Blvd. to get to the tavern.

B1

Rio Dr. and Elm St. facing north

Go straight on Elm St. Turn toward the mall on Burbank Blvd. Turn toward the gas station on Lemon Ave. Turn toward the park on Main St. Turn toward the hospital on Memory Lane to get to the hospital.

Go north on Elm St. Turn west on Burbank Blvd. Turn north on Lemon Ave. Turn west on Main St. Turn north on Memory Lane to get to the hospital. 
Table 1: (continued)

\begin{tabular}{ll}
\hline Route & Starting Point \\
B2 & Florence Blvd. and Pine St. facing north
\end{tabular}

Go straight on Pine St. Turn toward the courthouse on Wilson Rd. Turn toward the park on Division St. Turn toward the church on Henry. Turn toward the bank on Silver Lake Rd. to get to the post office.

Go north on Pine St. Turn west on Wilson Rd. Turn south on Division St. Turn west on Henry. Turn north on Silver Lake Rd. to get to the post office.

B3 Lemon Ave. and Neal St. facing west

Go straight on Neal St. toward the Library. Turn onto Oak St. Turn toward the Courthouse on Wilson Rd. Turn toward the park on Division St. Turn toward the monument on Main St. to get to the monument.

Go west on Neal St. Turn north on Oak St. Turn west on Wilson Rd. Turn south on Division St. Turn west on Main St. to get to the monument.

B4 Main St. and Western Ave. facing north

Go toward the hospital on Western Ave. Turn toward the post office on Faulkner Blvd. Turn toward the monument on Silver Lake Rd. Turn toward the park on Main St. Turn toward the lake on Division St. to get to the lake.

Go north on Western Ave. Turn east on Faulkner Blvd. Turn south of Silver Lake Rd. Turn east on Main St. Turn south on Division St. to get to the lake.

B5 Lawrence Lane and Silver Lake Rd. facing west

Go toward the hospital on Lawrence Lane. Turn toward the church on Memory Lane. Turn toward the school on Henry. Turn toward the park on Division St. Turn toward the grocery store on Main St. to get to the grocery store.

Go west on Lawrence Lane. Turn south on Memory Lane. Turn east on Henry. Turn south on Division St. Turn east on Main St. to get to the grocery store.

B6 Kedzie Dr. and Division St. facing east

Go straight on Kedzie Dr. Turn toward the school on Rodeo Rd. Turn toward the grocery store on Main St. Turn toward the gas station on Lemon Ave. Turn toward the library on Neal St. to get to the library.

Go east on Kedzie Dr. Turn north on Rodeo Rd. Turn east on Main St. Turn north on Lemon Ave. Turn west on Neal St. to get to the library.

(i.e., keeping track of the relationship between one's own position and global reference points, such as cardinal directions) were summed to determine the orientation strategy score. Similarly, responses to the 5 questions related to route strategies (e.g., using step-by-step routes involving landmarks) were summed to determine the route strategy score. Higher scores indicated stronger reported preferences for the specified wayfinding strategies.

\section{Results}

The primary goal of this investigation was to specify the relations among spatial anxiety, wayfinding strategies, and navigation performance in our task. We 


\section{HUND, MINARIK}

expected that people who reported greater spatial anxiety would be less efficient when navigating. In addition, we predicted that self-reports of wayfinding strategies would be related to navigation efficiency in our task. In particular, as preferences for orientation strategies increased, we expected that navigation efficiency using cardinal directions would increase (e.g., faster navigation times and fewer errors). Similarly, as preferences for route strategies increased, navigation efficiency using landmark directions also should increase. A second goal was to examine the efficiency with which people navigate using directions containing landmarks and cardinal descriptors. We expected that women would be faster and more accurate when following landmark directions than when following cardinal directions, whereas men would be faster and more accurate when following cardinal directions than when following landmark directions. Finally, we expected that navigation efficiency would improve with experience in our behavioral navigation task.

\section{Spatial Anxiety}

To investigate the relation between spatial anxiety and navigation efficiency, we examined the correlation between self-reported spatial anxiety and navigation performance in our task. As predicted, as spatial anxiety increased, navigation errors also increased significantly, $r(62)=.30, p<.05$. Similarly, as spatial anxiety increased, navigation time in our task increased, $r(62)=.19, n s$, though this result did not reach statistical significance. An unpaired $t$-test revealed that spatial anxiety did not differ for women $(M=19.38, S D=6.19)$ and men $(M=$ $18.34, S D=5.10), t(62)=.727, n s$ (see Table 2$)$.

\section{Wayfinding Strategies}

To assess the relation between wayfinding strategies and navigation efficiency, we examined the correlation between wayfinding strategies and navigation efficiency using each direction type. As expected, as reported reliance on orientation strategies increased, navigation time based on cardinal directions decreased significantly, $r(62)=-.33, p<.01$. As reported reliance on route

Table 2

Mean Spatial Anxiety, Wayfinding Strategies, Navigation Time, and Navigation Errors in Experiment 1

\begin{tabular}{lrr}
\hline \multicolumn{1}{c}{ Measure } & Men & Women \\
\hline Spatial Anxiety & $18.34(5.10)$ & $19.38(6.19)$ \\
Orientation Wayfinding Strategy & $29.94(7.30)$ & $28.22(7.40)$ \\
Route Wayfinding Strategy & $20.81(4.40)$ & $24.41(3.82)$ \\
Cardinal Navigation Time & $28.84(5.84)$ & $30.04(6.68)$ \\
Landmark Navigation Time & $33.06(6.32)$ & $33.07(5.69)$ \\
Cardinal Navigation Errors & $1.81(1.69)$ & $1.38(2.04)$ \\
Landmark Navigation Errors & $3.00(2.79)$ & $2.00(1.48)$ \\
\hline
\end{tabular}

Note. Standard deviations are listed in parentheses. 
strategies increased, navigation time based on landmark directions decreased, though the effect was only marginally significant, $r(62)=-.24, p=.06$. We also examined the correlation between each wayfinding strategy and overall navigation efficiency. As reliance on orientation strategies increased, overall navigation time in our task decreased significantly, $r(62)=\quad-.32, p<.05$. In contrast, there was no significant relation between reliance on route strategies and overall navigation time in our task, $r(62)=.02, n s$. Neither wayfinding strategy was related to navigation errors in our task, $|r| \mathrm{s}(62)<.19$, $n s$. We used unpaired $t$-tests to examine gender differences in wayfinding strategies. Women $(M=24.41, S D=3.82)$ reported significantly greater reliance on route strategies than did men $(M=20.81, S D=4.40), t(62)=3.49, p<.01$. Men $(M=29.94$, $S D=7.30)$ and women $(M=28.22, S D=7.40)$ reported similar levels of reliance on orientation strategies, $t(62)=-.94, n s$ (see Table 2).

\section{Navigation Efficiency as a Function of Information Type and Gender}

To determine how efficiently men and women navigate using cardinal and landmark directions, mean navigation time and total errors were analyzed using separate Information Type (landmark v. cardinal) $\times$ Gender (women v. men) mixed model analyses of variance (ANOVAs). The navigation time analysis revealed a significant main effect of information type, $F(1,62)=29.64, p<.01$. Participants were significantly faster when following cardinal directions $(M=$ $29.44, S D=6.25)$ than when following landmark directions $(M=33.06, S D=$ 5.96, see Table 2). Contrary to our expectations, neither the main effect of gender, $F(1,62)=.19, n s$, nor the Information Type $\times$ Gender interaction, $F(1$, $62)=.80, n s$, reached statistical significance.

The analysis of errors revealed a significant main effect of information type, $F(1,62)=6.19, p<.05$. Participants made significantly fewer errors when following cardinal directions $(M=1.59, S D=1.88)$ than when following landmark directions $(M=2.50, S D=2.28$, see Table 2). Again, neither the main effect of gender, $F(1,62)=3.87$, ns, nor the Information Type $\times$ Gender interaction, $F(1,62)=.60, n s$, reached statistical significance.

\section{Improvements in Navigation Efficiency over Trials}

Given our interest in understanding the dynamics of wayfinding, we examined whether navigation efficiency improved across trials in our task. To address this issue, navigation times for the first three trials and the last three trials involving each information type were entered into a repeated-measures ANOVA. Results revealed a significant main effect of trials, $F(1,63)=116.29, p<.001$. Participants navigated significantly faster on the last three trials of each type ( $M$ $=28.51, S D=5.53)$ than on the first three trials $(M=33.95, S D=6.13)$, indicating that their navigation performance improved with experience. We did not to analyze changes in navigation errors over trials because the overall numbers of errors was low, leading to possible floor effects. 


\section{Discussion}

The primary goal of this investigation was to examine the relations among spatial anxiety, wayfinding strategies, and navigation efficiency. As expected, as spatial anxiety increased, navigation errors and time also increased, though the magnitude of these significant correlations was modest. It is possible that these modest relations reflect the complex nature of spatial anxiety and navigation efficiency, as well as their interrelations. Moreover, as reliance on orientation strategies increased, overall navigation time and navigation time based on cardinal directions decreased, suggesting that participants reporting a preference for orientation strategies were more efficient navigators. Moreover, as reliance on route strategies increased, navigation time based on landmark directions decreased. Importantly, these findings indicate that spatial anxiety and wayfinding strategies are related to wayfinding performance in a behavioral task, thereby clarifying the nature of these relations (for similar results, see Lawton, 1994, 1996; Pazzaglia \& DeBeni, 2001; see also Saucier et al., 2002). We also examined gender differences in spatial anxiety and wayfinding strategies. As expected, women reported significantly greater reliance on route strategies than did men. Contrary to our predictions, however, spatial anxiety did not differ significantly for women and men. It is unclear why gender differences in spatial anxiety are inconsistent across experiments (e.g., Lawton, 1994, 1996; Lawton \& Kallai, 2002; Lawton et al., 1996; Prestopnik \& Roskos-Ewoldsen, 2000; Saucier et al., 2002; for a recent review, see Montello et al., 1999), though it may reflect the complexity of the relation between spatial anxiety and performance.

A second goal of the present investigation was to investigate whether men and women were more efficient when navigating based on directions containing landmarks or cardinal descriptors. Unexpectedly, participants were faster and more accurate when following cardinal directions than when following landmark directions. Moreover, navigation time and errors did not differ for men and women as a function of direction type. Why might these results differ from previous findings in the literature documenting an advantage for women when following directions containing landmarks (e.g., Saucier et al., 2002; see also Galea \& Kimura, 1993; MacFadden et al., 2003; Ward et al., 1986)? One possibility is that navigation efficiency differs depending on the scale of the space and the perspective of the navigator. Many of the tasks that have shown an advantage for landmark directions (among women) have involved large-scale spaces in which participants experience a ground-level perspective as they move through the environment (e.g., Lawton, 1996; Lawton et al., 1996; Experiment 1 in Saucier et al., 2002). In contrast, our task involved a small model town, which allowed participants to navigate based on an overhead perspective. This difference may affect the salience and utility of landmarks and cardinal descriptors for aiding navigation. However, this explanation is complicated by the fact that some previous tasks have included small-scale spaces (e.g., maps) that provided an overhead view of the navigable space (e.g., Experiment 2 in 
Saucier et al., 2002). As such, additional research is needed to determine how scale and viewer perspective may lead to differences in the relative efficiency of navigation based on landmark and cardinal directions observed here and in the literature (see Shelton \& McNamara, 2004; Taylor \& Tversky, 1996 for related theoretical ideas). In particular, it is critical to manipulate systematically scale and perspective while keeping other task demands as similar as possible to clarify these important issues.

A second possibility is that gender differences in navigation efficiency differ across experiments because the information provided in the directions and environmental layout was different. In previous research, directions involving Euclidean descriptors included distances and cardinal directions, whereas directions involving route descriptors included left and right turns and landmarks. In contrast, the current investigation included only cardinal directions and landmarks, not distances and left-right turns. That is, we equated the amount of information given to participants in the written directions by holding all information constant except for the critical manipulation of direction type (i.e., cardinal or landmark, see Table 1). Our aim was to focus on the difference between cardinal and landmark descriptors in the absence of differences related to distance and left-right turns. It is also possible that differences in the familiarity and layout of the environment led to differences across experiments. Although participants in this experiment were shown all of the landmarks in the model town and given time to become familiar with the overall layout, this familiarization might not have been sufficient for them to be confident using the many landmarks included. In contrast, people may have been more confident concerning the four cardinal directions, which were presumably known already and simply needed to be pointed out for our model town. Moreover, the layout of streets in our fictitious town was fairly regular and coincided with the cardinal directions (e.g., north, south, east, west), making this information particularly easy to use in our task. It is also possible that the landmarks were less distinctive than were the cardinal directions (and than landmarks in everyday environments), decreasing people's confidence in using the landmarks to navigate. Future research involving a variety of environments and tasks is needed to clarify these issues.

A third possibility is that design differences account for differences across experiments. Previous experiments that have documented differences in navigation efficiency using landmarks and cardinal descriptors have employed different groups of participants in each condition (i.e., using a between-subjects design). In contrast, Experiment 1 used a within-subjects design, in which participants navigated using both types of directions. We adopted a betweensubjects design in Experiment 2 to in an attempt to determine whether design differences account for the divergent pattern of results.

Given the somewhat unexpected nature of our results, Experiment 2 was designed to determine whether the direction type and gender differences observed in the first experiment were replicable. Importantly, Experiment 2 used a between-subjects design to assess navigation efficiency using landmarks and 


\section{HUND, MINARIK}

cardinal directions. We hypothesized that people would be more efficient when following cardinal directions than when following landmark directions, replicating the results from Experiment 1. We also expected that navigation efficiency would improve over trials, as it did in Experiment 1, demonstrating the importance of experience and the dynamic nature of wayfinding.

\section{EXPERIMENT 2}

\section{Method}

\section{Participants}

Ninety-two participants (46 men and 46 women) volunteered to participate in this study. Data from two additional male participants were excluded from the final data set because their navigation times were greater than two standard deviations above the mean. Participants were recruited and compensated in the same manner as in Experiment 1. Their ages ranged from 18 years 6 months to 41 years 5 months ( $M=20$ years 11 months).

\section{Materials and Apparatus}

The model town, toy car, and stopwatch were identical to those used in the previous experiment. As in Experiment 1, participants were given a set of note cards with routes printed on them.

\section{Design and Procedure}

Participants were randomly assigned to one of two conditions: landmark or cardinal. In the landmark condition, all of the routes included landmarks, whereas in the cardinal condition, all of the routes included cardinal descriptors. The order of the routes (i.e., $\mathrm{AB}$ or $\mathrm{BA}$ ) was counterbalanced across participants. As in Experiment 1, participants followed a specific set of directions by moving a toy car from a starting location to a destination on each of 12 trials. Navigation time and errors were coded in the same manner as in Experiment 1.

\section{Results}

\section{Navigation Efficiency as a Function of Information Type and Gender}

Mean navigation times and total navigation errors were analyzed using separate Condition (landmark v. cardinal) $\times$ Gender (women v. men) ANOVAs with two between-subjects factors. The analysis of navigation time revealed a significant main effect of condition, $F(1,88)=8.14, p<.01$. As in Experiment 1 , participants were significantly faster when following cardinal directions $(M=$ $26.18, S D=5.36)$ than when following landmark directions $(M=29.42, S D=$ 5.71). The analysis also yielded a significant main effect of gender, $F(1,88)=$ $4.46, p<.05$. Men navigated significantly faster $(M=26.60, S D=5.90)$ than did 
GETTING FROM HERE TO THERE 193

Table 3

Mean Navigation Time and Errors in Experiment 2

\begin{tabular}{lrr}
\hline \multicolumn{1}{c}{ Measure } & \multicolumn{1}{c}{ Men } & \multicolumn{1}{c}{ Women } \\
\hline Cardinal Navigation Time & $25.24(5.66)$ & $27.12(4.99)$ \\
Landmark Navigation Time & $27.96(5.94)$ & $30.89(5.18)$ \\
Cardinal Navigation Errors & $1.96(1.61)$ & $1.96(2.16)$ \\
Landmark Navigation Errors & $2.70(2.29)$ & $3.13(2.26)$ \\
\hline
\end{tabular}

Note. Standard deviations are listed in parentheses.

women $(M=29.00, S D=5.38$, see Table 3$)$. As in Experiment 1 , the Gender $\times$ Condition interaction did not reach statistical significance, $F(1,88)=.21$, $n s$.

The analysis of navigation errors revealed a significant main effect of condition, $F(1,88)=4.78, p<.05$. As in the first experiment, participants made significantly fewer errors when following cardinal directions $(M=1.96, S D=$ 1.89) than when following landmark directions $(M=2.91, S D=2.26)$. Navigation errors did not differ for men $(M=2.33, S D=1.99)$ and women $(M=$ $2.54, S D=2.27), F(1,88)=.25$, $n s$ (see Table 3 ), nor did they differ as a function of gender and direction type, $F(1,88)=.25, n s$.

\section{Improvements in Navigation Efficiency over Trials}

Given our interest in understanding the dynamics of wayfinding, we examined whether navigation efficiency improved across trials in our task. To address this issue, navigation times for Trials 1 through 3,4 through 6,7 through 9 , and 10 through 12 were entered into a Trial Block (Block 1: Trials 1-3, Block 2: Trials 4-6, Block 3: Trials 7-9, Block 4: Trials 10-12) $\times$ Condition repeated-measures ANOVA. Results revealed a significant main effect of trial block, $F(3,270)=$ 78.47, $p<.001$. Participants navigated significantly slower during the first trial block $(M=31.45, S D=7.31)$ than during the second $(M=26.39, S D=5.87)$, third $(M=25.35, S D=5.92)$, and fourth $(M=26.19, S D=5.75)$ blocks of trials. Moreover, they navigated significantly slower during Block 2 than during Block 3. Navigation times for the remaining pair-wise comparisons across trial blocks did not differ significantly. Together, these findings indicate that navigation performance improved with experience. As in Experiment 1, we did not to analyze changes in navigation errors over trials because the overall numbers of errors was low, leading to possible floor effects.

\section{Discussion}

Our main objective was to examine how quickly and accurately men and women navigated based on directions containing landmarks and cardinal descriptors. As in the first experiment, participants navigated significantly faster and more accurately when following cardinal directions than when following landmark directions. These findings indicate that the differences in navigation performance evident here versus in the literature cannot be attributed to the 


\section{HUND, MINARIK}

pattern of manipulation of the direction type variable (i.e., within- v. betweensubjects). Although several previous studies have shown that men outperform women when using survey cues (such as cardinal directions) to navigate and women outperform men with using route cues (such as landmarks, Galea \& Kimura, 1993; Lawton, 1994, 1996; Lawton et al., 1996; Miller \& Santoni, 1986; Montello et al., 1999; Pazzaglia \& DeBeni, 2001; Ward et al., 1986), these gender differences remain controversial. In particular, the advantage for survey cues is more widely established than is the advantage for route cues (Devlin \& Bernstein, 1995, 1997; Montello et al., 1999). The results from the present investigation are consistent with this latter proposal, supporting the overall advantage for survey cues, rather than the more nuanced pattern of preferences based on gender. Similarly, previous findings suggest that people take longer to read texts containing landmarks and left-right turns than texts containing cardinal directions and distances (Taylor \& Tversky, 1992). Thus, it is possible that landmark directions are inherently more difficult to comprehend than are cardinal directions.

Unlike Experiment 1, men navigated significantly faster than did women, though navigation errors did not differ for men and women. This gender difference in navigation time is consistent with previous findings suggesting an advantage for men in navigation tasks (e.g., Bell \& Saucier, 2004; Galea \& Kimura, 1993; Lawton, 1994; Montello et al., 1999; Saucier et al., 2002; Sholl et al., 2000; Ward et al., 1986). It is not clear why gender differences emerge in some tasks but not in others. One possibility is that sample characteristics affect findings relating to gender differences. For example, differences in participants' experiences with navigation and other spatial tasks may affect the overall pattern of results (e.g., Lawton \& Kallai, 2002; Stern \& Portugali, 1999). Differences in sample size also may affect the pattern of results. In the present investigation, gender differences emerged in Experiment 2, which included a larger sample, but not in Experiment 1. Future research is needed to further clarify these issues.

A second goal of this investigation was to further demonstrate differences in navigation efficiency over time. As in Experiment 1, our behavioral measure of navigation time revealed clear improvements in performance over trial blocks, suggesting that navigation efficiency improves with experience. Although previous research demonstrating changes in navigation efficiency over learning are scarce, these findings are consistent with others showing real-time, learning time, and developmental changes in memory performance (e.g., Engebretson \& Huttenlocher, 1996; Hund \& Plumert, 2002, 2005; Hund \& Spencer, 2003; Huttenlocher, Hedges, \& Duncan, 1991; Schutte \& Spencer, 2002; Spencer \& Hund, 2002, 2003). Thus, the present findings offer important insights into the dynamics of wayfinding processes and spatial processes more generally.

\section{GENERAL DISCUSSION}

The goal of this investigation was to examine the relations among spatial anxiety, wayfinding strategies, and navigation efficiency using cardinal and 
landmark directions among men and women. Importantly, we found that as spatial anxiety increased, the number of errors and the time needed for navigation increased. Moreover, as reliance on orientation strategies (e.g., maintaining a sense of northward direction during wayfinding) increased, navigation efficiency in our task overall and when using cardinal directions also increased. As reliance on route strategies (e.g., following a specified route during wayfinding) increased, navigation efficiency using landmark directions increased, though the magnitude of this effect was only marginally significant. These findings demonstrate that spatial anxiety and wayfinding strategies are related to behavioral measures of navigation. We also found that men and women were faster and more accurate when navigating based on cardinal directions than when navigating based on landmark directions. This effect was replicated in a second experiment that utilized a between-subjects design.

Although wayfinding strategies and anxiety were related to navigation performance (i.e., speed and accuracy) in our task, these correlational findings preclude clear analysis of causal relations. It is possible that navigation performance determines strategies and anxiety. Conversely, it is possible that wayfinding strategies and anxiety lead to changes in navigation performance. Of course, it is also possible that a third variable leads to changes in both variables. Our contention is that navigation experience shapes performance, strategies, and anxiety. If experience navigating through the environment accounts for the relation between wayfinding strategies and anxiety and navigation performance, experience might also account for individual differences in navigation abilities. For example, Ward et al. (1986) suggested that driving experience, geography courses, and activities involving cardinality might account for gender differences in navigation tasks (see also Kozlowski \& Bryant, 1977). Moreover, Lawton and Kallai (2002) found that navigation experiences during childhood and adulthood were related to individual differences in skills.

One way to test these claims is to examine the emergence of spatial experiences and skills over time. The present findings clearly indicate that navigation efficiency improves dramatically over trial blocks, suggesting that experience during a relatively brief task affects navigation performance. Recently, Allen and his colleagues (Allen, 1999b; Ondracek \& Allen, 2000) examined changes in spatial experience and skills over a broader, developmental time scale, specifying the origins of navigation abilities. For example, Allen (1999b) examined 8- and 10-year-old children's ability to remember and infer spatial information from descriptions of spatial layouts (e.g., a music room). Participants heard descriptions of 3 spatial layouts. Each was described using a different perspective: a survey perspective (i.e., using cardinal directions), a route perspective (i.e., using a route through the space), and a vantage point perspective (i.e., using one perspective, but using left and right rather than cardinal directions). Following learning, participants verified the truth of statements regarding the space. Children were more accurate following learning based on vantage point descriptions than following learning based on the other types of descriptions. In a similar set of studies, Ondracek and Allen (2000) 


\section{HUND, MINARIK}

gave 6- and 8-year-olds verbal descriptions of three spaces and asked them to verify statements about the spaces. In addition, the children attempted to place tokens of the objects on a map of the space. Older children were more accurate in verifying statements and in placing the tokens on a map than were the younger children. As in the previous study, older children were most accurate following learning based on vantage point descriptions. In contrast, younger children were most accurate following learning based on route perspective descriptions, suggesting that reliance on landmark directions may emerge earlier than reliance on cardinal and vantage point directions.

Ondracek and Allen tested this assertion by conducting a second experiment that included an intervention designed to improve children's understanding of directional terms. Children first heard one description. Then, half of the children viewed a map (which included labels of north, left, and right) while listening to a description. Finally, everyone heard another description and completed the verification and map placement tasks. Children who viewed the labeled map during the second description were more accurate than were the children who did not view the labeled map. These findings provide initial support for the notion that experience is crucial in shaping navigation strategies and performance (see also Lawton \& Kallai, 2002; Stern \& Portugali, 1999; Taylor \& Naylor, 2002; Taylor et al., 1999; Taylor \& Tversky, 1992). Future research should continue to specify how experience over multiple time scales shapes navigation abilities to more fully understand these underlying processes.

In summary, the present investigation revealed that as spatial anxiety increased, navigation efficiency decreased, and as preference for orientation (survey) strategies increased, overall navigation efficiency increased. In addition, men and women were faster and more accurate when navigating based on cardinal directions than when following landmark directions. These results add to a growing body of literature documenting the importance of cardinal and landmark descriptors for direction following (e.g., Galea \& Kimura, 1993; Lawton, 1994, 1996; Lawton \& Kallai, 2002; Montello et al., 1999; Saucier et al., 2002; Ward et al., 1986). More generally, they support the notion that people can use both survey and route perspectives to understand space and to navigate efficiently.

These findings indicate that many factors affect navigation efficiency. For example, the directions provided (e.g., cardinal or landmark) influence navigation efficiency (Galea \& Kimura, 1993; Lawton \& Kallai, 2002; Saucier et al., 2002). The structure of the environment also shapes navigation. For instance, people are more likely to provide route descriptions when the available landmarks are similar in size and an obvious path is available (Taylor \& Tversky, 1996; see Lawton, 2001 for regional differences). Individual differences in spatial abilities, navigation skills, and navigation experiences also affect performance. In fact, the present findings add to the growing literature documenting the importance of navigation strategies (Hirtle \& Hudson, 1991; Kozlowski \& Bryant, 1977; Lawton, 1994, 1996; Lawton \& Kallai, 2002; Montello \& Pick, 1993; Pazzaglia \& DeBeni, 2001; Stern \& Portugali, 1999). 
Moreover, the nature of the wayfinding task (e.g., describing a space versus giving directions to a traveler; Plumert et al., 1995; learning via direct travel through a space versus a map of a space, Moeser, 1988; learning a route versus learning the overall layout, Taylor \& Naylor, 2002), coordination among communicators (e.g., selecting a perspective or frame of reference, assessing the familiarity of the environment, understanding individual skills and preferences; Taylor \& Tversky, 1992), and cultural conventions for communication (CarlsonRadvansky \& Radvansky, 1996; Levinson, 1996; for developmental analyses see Allen, Kirasic, \& Beard, 1989; Plumert, Pick, Marks, Kintsch, \& Wegesin, 1994; Plumert \& Strahan, 1997) all affect direction giving and following. The present findings support the notion that people flexibly combine a variety of cues to navigate effectively in the task at hand, consistent with a dynamic view of wayfinding (Hirtle \& Heidorn, 1993; Montello, Hegarty, Richardson, \& Waller, 2004; Newcombe \& Huttenlocher, 2000; Plumert et al., 1995; Schober, 1993, 1995; Shelton \& McNamara, 2004). Future research is needed to further clarify how spatial anxiety, wayfinding strategies, and direction type are related to wayfinding efficiency across a variety of task contexts. This work is critical to understanding the dynamic processes involved in skillful navigation.

\section{ACKNOWLEDGMENTS}

We thank Kimberly Hopkins, Laura Noonan, Deah Partak, and Emily Slechta for their help with data collection and coding and Carol Lawton for permission to use her self-report scales. Portions of this research were presented at the 2004 conference of the Cognitive Science Society and the Illinois State University Undergraduate Research Symposium.

\section{REFERENCES}

Allen, G. L. (1999a). Spatial abilities, cognitive maps, and wayfinding: Bases for individual differences in spatial cognition and behavior. In R. G. Golledge (Ed.), Wayfinding behavior: Cognitive mapping and other spatial processes (pp. 46-80). Baltimore: Johns Hopkins University Press.

Allen, G. L. (1999b). Children's control of reference systems in spatial tasks: Foundations of spatial cognitive skill? Spatial Cognition and Computation, 1, 413-429.

Allen, G. L., Kirasic, K. C., \& Beard, R. L. (1989). Children's expressions of spatial knowledge. Journal of Experimental Child Psychology, 48, 114-130.

Bell, S., \& Saucier, D. (2004). Relationship among environmental pointing accuracy, mental rotation, sex, and hormones. Environment \& Behavior, 36, 251-265.

Bryant, K. J. (1982). Personality correlates of sense of direction and geographical orientation. Journal of Personality and Social Psychology, 43, 1318-1324. 


\section{HUND, MINARIK}

Carlson-Radvansky, L. A., \& Radvansky, G. A. (1996). The influence of functional relations on spatial term selection. Psychological Science, 7, 5660.

Denis, M., Pazzaglia, F., Cornoldi, C., \& Bertolo, L. (1999). Spatial discourse and navigation: An analysis of route directions in the city of Venice. Applied Cognitive Psychology, 13, 145-174.

Devlin, A. S., \& Bernstein, J. (1995). Interactive wayfinding: Use of cues by men and women. Journal of Environmental Psychology, 15, 23-38.

Devlin, A. S., \& Bernstein, J. (1997). Interactive way-finding: Map style and effectiveness. Journal of Environmental Psychology, 17, 99-110.

Engebretson, P. H., \& Huttenlocher, J. (1996). Bias in spatial location due to categorization. Comment on Tversky and Schiano. Journal of Experimental Psychology: General, 125, 96-108.

Galea, L. A. M., \& Kimura, D. (1993). Sex differences in route learning. Personality and Individual Differences, 14, 53-65.

Golledge, R. G. (1987). Environmental cognition. In D. Stokols \& I. Altman (Eds.), Handbook of environmental psychology (pp. 131-174). New York: Wiley.

Golledge, R. G. (1999). Human wayfinding and cognitive maps. In R. G. Golledge (Ed.), Wayfinding behavior: Cognitive mapping and other spatial processes (pp. 5-45). Baltimore: Johns Hopkins University Press.

Hirtle, S. C., \& Heidorn, P. B. (1993). The structure of cognitive maps: Representations and processes. In T. Garling \& R. G. Golledge (Eds.), Behavior and environment: Psychological and geographical approaches ( $\mathrm{p}$. 170-192). New York: Elsevier.

Hirtle, S. C., \& Hudson, J. (1991). Acquisition of spatial knowledge for routes. Journal of Environmental Psychology, 11, 335-345.

Hund, A. M., \& Plumert, J. M. (2002). Delay-induced bias in children's memory for location. Child Development, 73, 829-840.

Hund, A. M., \& Plumert, J. M. (2005). The stability and flexibility of spatial categories. Cognitive Psychology. 50, 1-44.

Hund, A. M., \& Spencer, J. P. (2003). Developmental changes in the relative weighting of geometric and experience-dependent location cues. Journal of Cognition and Development, 4, 3-38.

Huttenlocher, J., Hedges, L. V., \& Duncan, S. (1991). Categories and particulars: Prototype effects in estimating spatial location. Psychological Review, 98, 352-376.

Jansen-Osmann, P. (2002). Using desktop virtual environments to investigate the role of landmarks. Computers in Human Behavior, 18, 427-436.

Kozlowski, L. T., \& Bryant, K. J. (1977). Sense of direction, spatial orientation, and cognitive maps. Journal of Experimental Psychology: Human Perception and Performance, 3, 590-598.

Lawton, C. A. (1994). Gender differences in way-finding strategies: Relationship to spatial ability and spatial anxiety. Sex Roles, 30, 765-779. 
Lawton, C. A. (1996). Strategies for indoor wayfinding: The role of orientation. Journal of Environmental Psychology, 16, 137-145.

Lawton, C.A. (2001). Gender and regional differences in spatial referents used in direction giving. Sex Roles. 44, 321-337.

Lawton, C. A., Charelston, S. I., \& Zieles, A. S. (1996). Individual and gender related differences in indoor wayfinding. Environment \& Behavior, 28, 204219.

Lawton, C., \& Kallai, J. (2002). Gender differences in wayfinding strategies and anxiety about wayfinding: A cross-cultural comparison. Sex Roles, 47, 389401.

Levinson, S. C. (1996). Frames of reference and Molyneux's question: Crosslinguistic evidence. In P. Bloom, M. A. Peterson, L. Nadel, \& M. F. Garrett (Eds.), Language and space (pp. 109-169). Cambridge, MA: MIT Press.

MacFadden, A., Elias, L., \& Saucier, D. (2003). Males and females scan maps similarly, but give directions differently. Brain \& Cognition, 53, 297-300.

Mark, D. M., \& Gould, M. D. (1995). Wayfinding directions as discourse: Verbal directions in English and Spanish. In J. Duchan, G. Bruder, \& L. Hewitt (Eds.), Deixis in narrative: A cognitive science perspective (pp. 387405). Hillsdale, NJ: Erlbaum.

Miller, L. K., \& Santoni, V. (1986). Sex differences in spatial abilities: Strategic and experiential correlates. Acta Psychologica, 62, 225-235.

Moeser, S. D. (1988). Cognitive mapping in a complex building. Environment and Behavior, 20, 21-49.

Montello, D. R., Hegarty, M., Richardson, A. E., \& Waller, D. (2004). Spatial memory of real environments, virtual environments, and maps. In G. L. Allen (Ed.), Human spatial memory: Remembering where (pp. 251-285). Mahwah, NJ: Erlbaum.

Montello, D. R., Lovelace, K. L., Golledge, R. G., \& Self, C. M. (1999). Sexrelated differences and similarities in geographic and environmental spatial abilities. Annals of the Association of American Geographers, 89, 515-534.

Montello, D. R., \& Pick, H. L., Jr. (1993). Integrating knowledge of vertically aligned large-scale spaces. Environment and Behavior, 25, 457-484.

Newcombe, N. S., \& Huttenlocher, J. (2000). Making space: The development of spatial representation and reasoning. Cambridge, MA: MIT Press.

Ondracek, P. J., \& Allen, G. L. (2000). Children's acquisition of spatial knowledge from verbal descriptions. Spatial Cognition and Computation, 2, $1-30$.

Pazzaglia, F., \& DeBeni, R. (2001). Strategies of processing spatial information in survey and landmark centered individuals. European Journal of Psychology, 13, 493-508.

Plumert, J. M., Carswell, C., DeVet, K., \& Ihrig, D. (1995). The content and organization of communication about object locations. Journal of Memory and Language, 34, 477-498.

Plumert, J. M., Pick, H. L., Jr., Marks, R. A., Kintsch, A. S., \& Wegesin, D. (1994). Locating objects and communicating about locations: Organizational 


\section{HUND, MINARIK}

differences in children's searching and direction-giving. Developmental Psychology, 30, 443-453.

Plumert, J. M., \& Strahan, D. (1997). Relations between task structure and developmental changes in children's use of spatial clustering strategies. British Journal of Developmental Psychology, 15, 495-514.

Prestopnik, J. \& Roskos-Ewoldsen, B. (2000). The relations among wayfinding strategy use, sense of direction, sex, familiarity, and wayfinding ability. Journal of Environmental Psychology, 20, 177-191.

Saucier, D., Green, S., Leason, J., MacFadden, A., Bell, S., \& Elias, L. (2002). Are sex differences in navigation caused by sexually dimorphic strategies or by differences in the ability to use the strategies? Behavioral Neuroscience, 116, 403-410.

Schober, M. F. (1993). Spatial perspective-taking in conversation. Cognition, 47, 1-24.

Schober, M. F. (1995). Speakers, addressees, and frames of reference: Whose effort is minimized in conversations about locations. Discourse Processes, 20, 219-247.

Schutte, A. R., \& Spencer, J. P. (2002). Generalizing the dynamic field theory of the A-not-B error beyond infancy: Three-year-olds' delay- and experiencedependent location memory biases. Child Development, 73, 377-404.

Shelton, A. L., \& McNamara, T. P. (2004). Orientation and perspective dependence in route and survey learning. Journal of Experimental Psychology: Learning, Memory, and Cognition, 30, 158-170.

Sholl, J., Acacio, J., Makar, R., \& Leon C. (2000). The relation of sex and sense of direction to spatial orientation in an unfamiliar environment. Journal of Environmental Psychology, 20, 17-28.

Siegel, A. W., \& White, S. H. (1975). The development of spatial representations of large-scale environments. In H. W. Reese (Ed.), Advances in child development (pp. 37-55). New York: Academic Press.

Spencer, J. P., \& Hund, A. M. (2002). Prototypes and particulars: Geometric and experience-dependent spatial categories. Journal of Experimental Psychology: General, 131, 16-37.

Spencer, J. P., \& Hund, A. M. (2003). Developmental continuity in the processes that underlie spatial recall. Cognitive Psychology, 47, 432-480.

Stern, E., \& Portugali, J. (1999). Environmental cognition and decision making in urban navigation. In R. G. Golledge (Ed.), Wayfinding behavior: Cognitive mapping and other spatial processes (pp. 99-115). Baltimore: Johns Hopkins University Press.

Taylor, H. A., \& Naylor, S. J. (2002). Goal-directed effects on processing a spatial environment: Indications from memory and language. In K. R. Coventry \& P. Oliver (Eds.), Spatial language: Cognitive and computational perspectives (pp. 233-253). Dordrecht, Netherlands: Kluwer Academic Publishers. 
Taylor, H. A., Naylor, S. J., \& Chechile, N. A. (1999). Goal-specific influences on the representation of spatial perspective. Memory \& Cognition, 27, 309319.

Taylor, H. A., \& Tversky, B. (1992). Spatial mental models derived from survey and route descriptions. Journal of Memory and Language, 31, 261-292.

Taylor, H. A., \& Tversky, B. (1996). Perspective in spatial discourse. Journal of Memory and Language, 35, 371-391.

Ward, S. L., Newcombe, N., \& Overton, W. F. (1986). Turn left at the church, or three miles north: A study of direction giving and sex differences. Environment \& Behavior, 18, 192-213. 